\title{
Sensory Quality Profile of Ranah Minang Arabica Coffee Specialty
}

\author{
Rince Alfia Fadria, ${ }^{\mathrm{a}, 1}$, Kesuma Sayuti ${ }^{\mathrm{b}, 2}$, Novizar Nazir ${ }^{\mathrm{b}, 3}$, Irfan Suliansyah ${ }^{\mathrm{c}, 4}$ \\ ${ }^{a}$ Food Technology Study Program, Agricultural Polytechnic of Payakumbuh, Payakumbuh, Indonesia \\ ${ }^{b}$ Faculty of Agricultural Technology, Universitas Andalas, Padang, 25163, Indonesia \\ ${ }^{c}$ Faculty of Agriculture, Universitas Andalas, Padang, 25163, Indonesia

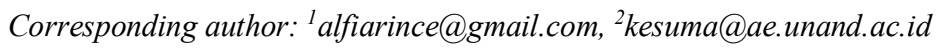

\begin{abstract}
Research has been conducted to determine the Minang domain arabica coffee sensory quality profile, which can be used as a reference for specialty coffee. Seed processing is carried out at the research location (Solok Regency, South Solok Regency, Pasaman, Agam, and Fifty Cities) until the grain stage is wet (washed). Fianda Coffee Roastery carries out the coffee roasting process. Coffee uses W600i Roaster with a long roast method with two treatments, namely temperature $1800 \mathrm{C}$ for 15 minutes, temperature $B 2000 \mathrm{C}$ for 10 minutes. The taste test was conducted at a two-door cafe and the Indonesian Coffee and Cocoa Research Institute Laboratory, Jember, East Java, following the SCAA. The test results showed that dry coffee beans' moisture content for all treatments was $<12 \%$. Testing of brewing quality characteristic shows that five local coffee origins (SC 1, SC 2, SC 3, SC 4, and SC 5) could meet the specialization qualifications under the SCAA Flavor Test Protocol (final score of at least 80) so that they meet the specifications for quality requirements as typical coffee from the Minang realm. The five Arabica coffee samples' taste quality is almost the same, but each has a unique aroma profile. The SC 1 and SC 2 coffee samples had a distinctive lemon (lemon) aroma, while SC 3 and SC 4 each had a honey-like aroma (honeyed), Herb aroma produced by SC 5, and SC1. Only SC 3 brewing produces a chocolaty aroma.
\end{abstract}

Keywords - Ranah Minang; specialty coffee; sensory quality; Arabica.

Manuscript received 25 Feb. 2020; revised 30 Aug. 2020; accepted 15 Nov. 2020. Date of publication 28 Feb. 2021. IJASEIT is licensed under a Creative Commons Attribution-Share Alike 4.0 International License.

\section{INTRODUCTION}

As the second-largest coffee exporting country in Asia, Indonesia has a rich type of coffee from each region known as specialty coffee. High production and consumption levels also increase counterfeiting rates and mixing seeds between high-quality coffee with low-quality coffee or ingredients other than coffee. A coffee market with a distinctive flavor (specialty taste) is overgrowing nowadays, especially in the main consumer countries. The coffee commodity that grows in West Sumatera is increasingly sought after by many coffee enthusiasts in the national and international markets, so the price increases. Arabica coffee from Ranah Minang, the region of West Sumatera Province, is one of the flagship export commodities in Indonesia that has been known in the domestic and international markets. According to the chairman of the Indonesian Plantation Farmers Association Group *(Gapperindo), West Sumatera predicted that the price of coffee from the domain of Ranah Minang would increase by $10-15 \%$ in 2019 . The price of West Sumatra Arabica Coffee in 2018 reaches IDR 130,000 per kilogram, increasing from the previous year, which ranged from IDR 90,000 to IDR 120,000 per kilogram.

Specialty Coffee is an assessment or classification of coffee with a special aroma and flavor with a minimum value of 80 and a maximum of 100. It does not have a significant defect in the green bean. Specialty Coffee is the term for coffee with the highest grade because it is processed specifically with special provisions, ranging from upstream to downstream. The quality of the sensory or specialty coffee flavor is very decisive, including consistency. Coffee taste quality-analyzed descriptively with Cup quality [1]-[3]. Cupping (cup quality) is a systematic method in evaluating the aroma and flavor of coffee samples and assessing the coffee beans to be sold, product quality control, development, and evaluation of new or mixed products (blend) to convince the material purchased. As desired and lastly, to get to know the flavor of the coffee.

Coffee has a very diverse character and flavor; each coffee variety has a distinct aroma and flavor. This difference in taste depends on the altitude, fertility condition, nutrient availability, and the chemical content of the land that becomes coffee planting media. Identification of flavor with wheel note 
Flavor reference, a circle chart-shaped tool containing flavor and aroma categories, for industrial use in determining the flavor of coffee to be assessed by the person who works as a sampling and coffee grader giver Called Q grader. The Coffee Quality Institute (CQI) International Institute ensures that distributed coffee is a specialty coffee that has been through the test stage. This is the advancement of the third Wave era, which is closely related to support the smooth coffee chain industry in terms of specialty coffee distribution. CQI created the Q Grader program to become the coffee era coordinator, ensuring that the coffee that is distributed is specialty coffee. To determine the characteristics of good coffee can also be seen from the standard Specialty Coffee Association of America ( $S C A A)$, it is the standard to see the characteristic flavor of coffee beans roasted and brewed by pay attention to the selection process of Coffee beans to be served. Rice coffee beans do not have a characteristic flavor of coffee but contain only precursor compounds (prospective) forming flavors.

New Coffee flavor character formed after coffee beans are roasted. There are complex chemical reactions during the roasting until formed the chemical components forming a characteristic coffee character. Up to now, it has been able to be detected more than 800 aroma forming chemical compounds; in addition, there are still many components that have not been detectable, including non-volatile compounds. During the roasting process, the coffee produced depends on the type of green coffee used, processing coffee beans, roasting, grinding, storage, and brewing method. The roasting of coffee beans changes the content chemically in coffee beans, accompanied by weight, increasing the size of coffee beans and color change of seeds. Roasted Coffee beans undergo a chemical change that is an element of delicious taste [4], [5].

Quality improvement of coffee is rated more important to do today considering the condition of the world Coffee Market that is more competitive. For consumers, the quality of coffee cannot be released from its good flavor. A variety of specialty coffee products then emerge as consumers' demand is higher than one of the coffee quality variables. The term of specialty coffee aims to the Arabica coffee products in certain regions that have distinctive properties prominent with stable quality, especially processed by the roaster, and traded specifically in the form of roasted coffee, ground coffee, or Brewing Coffee in certain retail markets [6], [7]. The determination of specialty coffee in Indonesia is still based on the location of the development (origin). In fact, the availability of broad genetic diversity provides the opportunity to conduct a selection of Single Cultivar Based Specialty Coffee, which grows in specific locations (single origin). Previous studies have proved to be a diversity of physical quality characteristics, biochemistry, and taste among Arabica coffee Cultivar [8]-[10].

Overseas, coffee beans are derived from a single cultivar that has been marketed as specialty coffees. Today, product identification and certification can even be done with molecular markers [11], [12]. With the emergence of a new specialty coffee single cultivar based, farmers are expected to obtain incentives in the form of higher prices for the crops of the cultivars concerned. The assessment of the quality of coffee is not simple but very complex, and many factors affect it, ranging from the level of on-farm to Off-farm [13]-[15].
Differences influence coffee quality in genetic factors (cultivars), altitude, and processing into rice seeds (green beans). Therefore, the interaction process of these three factors to the quality attribute of coffee becomes more complicated. Interactions research of various factors is still relatively limited. Based on the above, it is necessary to research to know the Ranah Minang Arabica Coffee's sensory quality profile, which can be used as a reference for specialty coffee.

\section{MATERIALS AND METHOD}

\section{A. Time and Place}

Seed processing is done at the research site (Solok Regency, South Solok, Pasaman, Agam, and Limapuluh Kota Regency) until the rice grain stage. The seed processing method is done by wet processing (full washed) [16], [17]. The wet processing method is done by means of harvested red coffee fruit mechanically peeled using a pulper machine to separate the skin of the fruit from the seeds, then fermented for 24 hours, and then it is washed until clean and directly dried by Sunlight. The quality testing of green coffee is done at Payakumbuh State Agricultural Polytechnic Laboratory. Fianda Coffee Roastery does the process of coffee roasting. Taste-testing known as cupping was done at Two Doors coffee cafe and Laboratory of Indonesian Coffee and Cocoa Research Center, Jember, East Java, following the standard Specialty Coffee Association of America (Specialty Coffee Association of America) [18]. The research had been done for eight months, from May to December 2019

\section{B. Tools and Materials}

The tools used in this study are pulper, sieve with size 30 and 75 mesh, stainless cups, thermometer, desiccator, digital scales, basin, plastic, measuring cup/chemical, pipette drops, filter paper, electric heating equipment, and cotton wool, $\mathrm{pH}$ meter, tester, Erlenmeyer, Volumetric flask, oven, Roaster machine Brand W600i and equipment for organoleptic test/cupping test. The materials used in this task are Single Origin Arabica Coffee from The Regency of Solok, South Solok, Pasaman, Agam, and Limapuluh Kota Regency Sigagar Utang Varieties using Fully washed processing.

\section{Roasting Method}

Coffee Roasting by W600i Roaster uses a long roast method with two treatments: temperature $180^{\circ} \mathrm{C}$ with a time of 15 minutes, $\mathrm{B}$ temperature $200^{\circ} \mathrm{C}$ with a time of 10 minutes. The Data obtained is analyzed using two-factors two-levels factorial design. Two-factors factorials are temperature and time, while two levels are high temperature and low temperature. The established factor is used to determine the temperature and the optimization time that can produce accepted coffee flavor by the community.

\section{Sensory Test Method/Cupping Test}

Coffee brewing quality tests and data analysis of rice coffee beans that are processed into ground coffee as much as $500 \mathrm{~g}$ for each treatment. The whole process of processing into ground coffee, as well as Coffee brewing quality test (cupping), was done at Two Doors Coffee Cafe and Laboratory of Indonesian Coffee and Cocoa Research Center, 
Jember, East Java, following the standard Specialty Coffee Association of America. Several expert panelists and Q grader did the brewing quality assessment. The tested quality attributes included aroma, flavor, body, acidity, aftertaste, sweetness, balance, clean cup, uniformity, defect, and overall, as well as the total score value (Specialty Coffee Association of America) [19].

Several things that must be considered by Q grader and trained panelists before doing the tastings are room conditions and the date of roasting samples. The ideal room has bright light and does not contaminate any smell because it can interfere with the color assessment of the brew and aromameanwhile, roasted samples not more than one week from the evaluation time. The tools in the cupping coffee technique are flavor note wheel and cupping spoon. The coffee cupping procedure starts by grinding the roasted coffee beans to smoothness level of medium-coarse or medium. Boil water up to $96{ }^{\circ} \mathrm{c}$. Sniff in the aroma of the coffee powder (first analysis). Note on the flavor note wheel. The coffee cupping technique uses a ratio of $150 \mathrm{ml}$ of water for 8.5 grams. Brew with a tubruk technique (Tubruk) Indonesian style coffee where coarse coffee grounds are boiled along with solid sugar) Let it brew for 4 minutes. Sniff in the scent again after brewed (second analysis). Note on the flavor note wheel. With a cupping spoon, remove the powder are on the surface to the edges, then sniff in the aroma (third analysis). Note on the flavor note wheel. Move the powder that is still on the surface to another container using a cupping spoon. Take a cupping spoon of the brewing water, sipping until filling the mouth. Note on the flavor note wheel.

\section{RESULTS AND DISCUSSION}

\section{A. Coffee Beans Quality Value}

The criteria for determining the quality of coffee beans refer to the physical test standard of Indonesian National Standard [18] and the standard of Specialty Coffee Association of America (SCAA) [19]. The physical test stages of coffee beans that are commonly done are water content test, Tracee test, defect test, color/smell test, and seed size test. The Minang Coffee Association in the Ranah Minang uses the criteria of physical quality value, water content, seed defect value, and land elevation for quality determination of coffee. Physical testing is a system used to assess the quality of coffee beans based on their physique, either using AIDS or using the human senses in accordance with the prevailing standards.

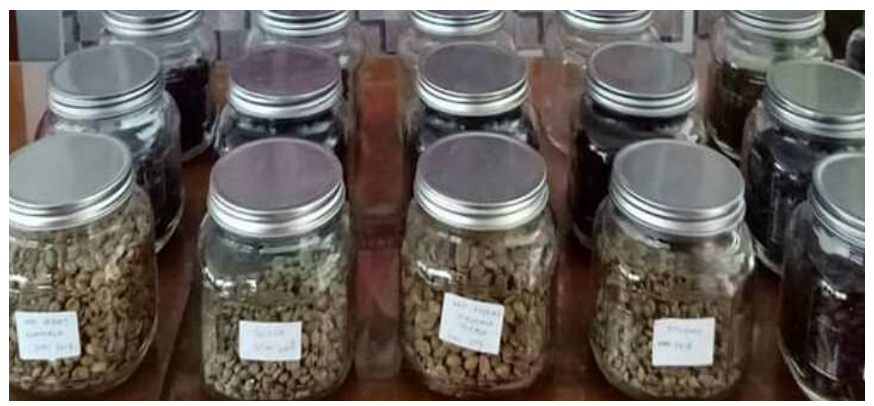

Fig. 1 West Sumatera Arabica coffee beans samples

1) Water Content Value: Visually observation shows that the color of coffee beans is darker with the length of time of fermentation. This indicates that microbial penetration into coffee beans is getting stronger with the growing length of fermentation time. There is a change in the color of coffee beans become darker. The test results showed the water content of dried coffee beans all the treatment of $<12 \%$ to meet the specification of the quality requirements SNI 012907-2008 [18]. Water content testing is carried out using a drying oven with weighing methods. The water content of the Ranah Minang Arabica coffee powder is available in Table 1.

TABLE I

West Sumatra Single Origin ARABiCa COFFEe BeAns WATER CONTENT VARIOUS OF VARIETY

\begin{tabular}{cc}
\hline Sample Codes & Water Content Average (\%) \\
\hline SC 1 & 10.5 \\
SC 2 & 10.7 \\
SC 3 & 10.8 \\
SC 4 & 11.1 \\
SC 5 & 11.6 \\
\hline
\end{tabular}

Water content testing shows the average sample has $10.94 \%$ or below $12 \%$ water content. The maximum water content is $11.6 \%$ and the lowest $10.5 \%$. Water content testing is very closely related to the potential of the growth of fungus that is widely found in coffee, such as Aspergillus Ochraceous and Aspergillus Niger, two types of fungus that cause ochratoxins (OTA). OTA is a toxin or toxic compound that becomes the standard quality of the coffee. Coffee importing countries have set the maximum content of OTA in coffee beans and its dairy products. Italy puts the maximum OTA content on coffee beans and processed coffee products, respectively, of 8 and 4 ppb [20]. Mycotoxins' existence in coffee is very detrimental to the country's trade/economy, especially the coffee-producing country [21], [22].

2) Triage Value: Triage is a percentage of defect seeds in 100 grams of coffee beans. Testing of Triage is done in a weighted manner where it is separated between the defect beans with normal beans, and the weighing result of defects beans is referred to as the percentage of triage. Test of Triage is done in the origin coffee beans, high or low of triage to present the quality of coffee beans.

3) Defect Value: The defect is the sum of the value of coffee beans defect, Test of Defect done when coffee beans are ready to export to determine the coffee's quality or grade. To determine defect can use two systems, namely the Indonesian National Standard and standard Specialty Coffee Association of America (SCAA) [19].

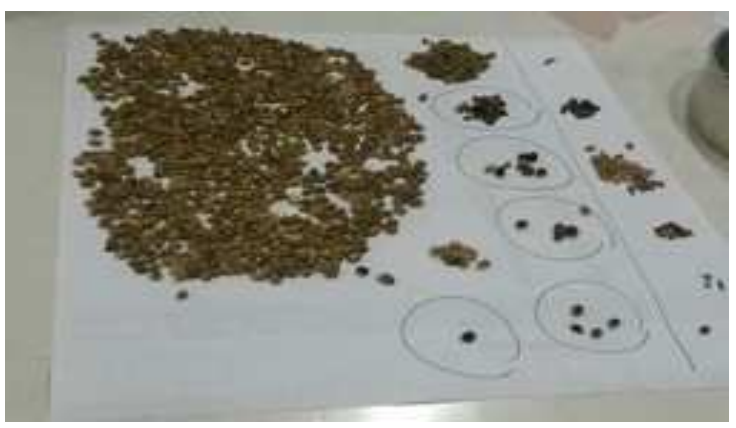

Fig. 2 Coffee Beans Quality Test

A physical quality test is a system used to assess the quality of coffee beans based on their physique, either using AIDS or 
using human senses according to the prevailing standards. The quality standard of coffee beans has been encouraged since 1978 through DECREE of the Minister of Trade No. $108 / \mathrm{Kp} / \mathrm{VII} / 78$ dated 1 July 1978 . The quality standard of coffee beans used is the triage system. But from October 1, 1983, until now, to determine the quality of coffee, Indonesia uses the Defects Value system following the decision of the International Coffee Organization (ICO). In this defect system, the more the value of the defect, the lower the coffee quality, and the smaller the defect's value, the better the quality of the coffee. Coffee beans are a coffee that is ready to be traded, the form of dried coffee beans that have been detached from the fruit flesh, horns skin, and skin.

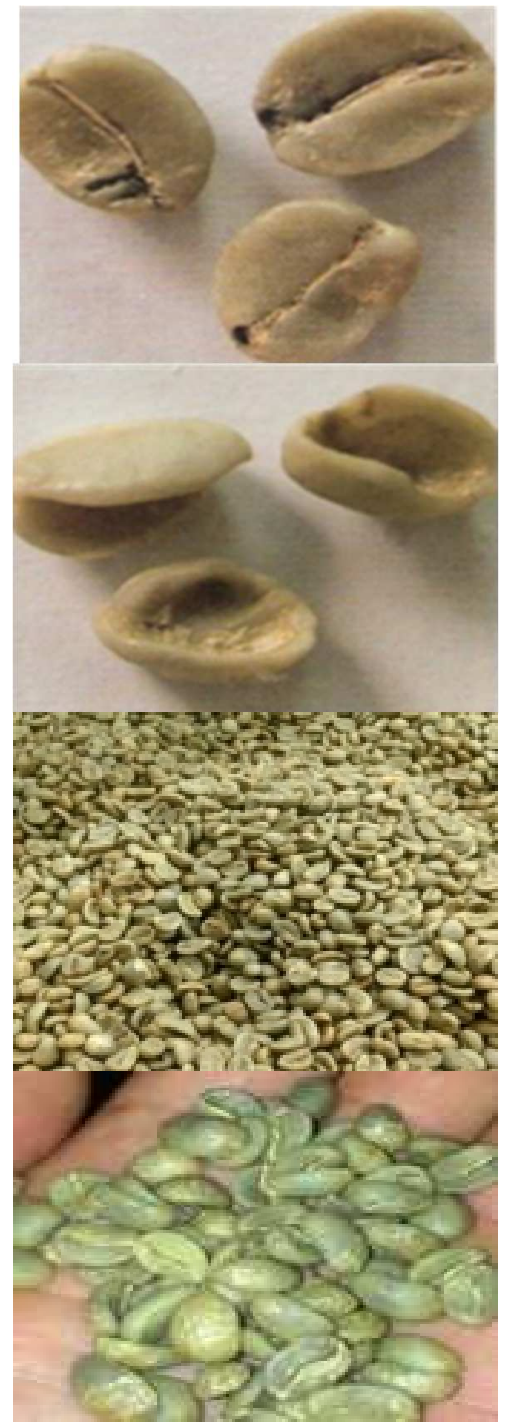

Coffee beans caused by insects that cause perforated beans and damaged beans due to postpicking or harvesting

Seeds are subjected to depreciation. The cause is due to drought and less fertile beans

Coffee beans in good condition, do not suffer damage and uninfected with coffee bean crop pests

Coffee beans in good condition, do not suffer damage and uninfected with coffee bean crop pests

Fig. 3 Defect of Ranah Minang Coffee Beans

The rupture bean is the coffee beans are not intact, have the same size or less than 3/4 parts of intact seeds. Young seeds are small coffee beans and wrinkles on all parts of the outside. This is due to the harvesting of the fruit that is too young. One hollowed bean is a coffee bean that is one hollowed due to an insect attack. More than one perforated bean are coffee beans that are perforated more than one due to insect attack. Spotted beans are coffee beans that are spotted on the outside. This is due to the pulper or washer, which is less appropriate (too tightly) so that injuries to the bean's surface. Rupture Black bean is black coffee beans that are not intact and have the same size or less than $3 / 4$ parts of intact beans. This black bean's rupture is due to the adjustment of pulper, washer, or huller that is too tightly, direct Peeling after drying or a very low water content coffee peeling [23]-[26]. The Black bean is a coffee bean that is half or more outside of it is black. Black coffee beans are caused by fruit disease and fruit decay during the hoarding or too young fruit picking. While the partly black beans are coffee beans are less than half the outside is black. This is due to injuries that occur during pulping or washing. The roll coffee is dried coffee fruit, or dried coffee beans are still wrapped in the fruit's skin. This is caused by the too highwater content of coffee in the time of peeling. The brown beans are a coffee bean that is half or more outside of brown. Red coffee beans are caused by overripe fruit harvesting, absorption of fruit flesh that is destroyed during bean fermentation, and imperfect washing or too dry drying temperatures. Therefore, the fermentation process is an important step in processing coffee in a wet manner, considering its positive influence on taste improvement [27], [28]. On physical sightings, Arabica coffee beans testing do not indicate the presence of mold or live insects. Thus, it meets the quality requirements according to the Indonesian National Standard; likewise, the aroma of arabica coffee beans do not indicate the presence of rotten smell like moss or rotten coffee skin. Before further processing, coffee beans are dried with the method of sunbathing.

Referring to the history of the implementation of quality standards on coffee commodity has existed since the Dutch era, then known as OVEIP or organizers Atie Verenigde Eksporteurs Van Indonesiche Producten. This organization is an institution that standardizes the commodity products exported from Indonesia. Subsequently applied TRIAGE system, or better known by a gross value system. The gross value in question is the coffee beans of black, brown, and crushed seeds. The quality standard of coffee beans has been encouraged since 1978 through DECREE of the Minister of Trade No. 108/Kp/VII/78 dated 1 July 1978. The quality standard of coffee beans used is the triage system. With the development of tastes and demand for coffee commodities, then on 1 October 1983, set the standard of coffee quality with the defect value system's name. Coffee Quality system is known quality coffee 1 to quality 6 . Renewal of quality standards with this system is intended to adjust Indonesian coffee's quality standards with a quality level system or qualities in a country, especially the coffee-producing country. The National Standardization Agency adopts this system in setting the Indonesian National Standard for coffee beans quality.

As time goes by, coffee beans Indonesian National Standard undergoes several changes, and the latest Standard used today is Indonesian National Standard No. 01-29072008. There is the definition and determination of the defect value for the type of coffee beans defect in this standard, and the quality classification based on the value of defects obtained. Defect in coffee is a sensation characteristic of unpleasant (negative) coffee flavor due to several factors. It includes the processing of green beans that are not careful, improper harvesting process, imprecision of water content During storage, or the presence of physical defects in coffee beans that cause taste defect or aroma defect. Renewal of 
quality standard with a flawed value system is also meant to adjust the quality standard of our coffee with a widely used system in various countries of coffee producers and be more easily understood by buyers from consumer countries. This defective value system is still used with only a few revisions [18], [19].

The provisions on bean quality at this time are generally based on the assessment on the content of coffee beans defect in the coffee bean party that is taken through examples or samples representing a coffee bean party. Determining the type or type of quality is based on the determination of Defect value [18], [19]. According to the International Coffee Organization (ICO), the consumption of coffee increased from year to year, so that the increase in coffee production in Indonesia can export coffee to the major coffee consumption countries in the world such as the Europe, America, and Japan. In Indonesia, coffee beans are also supplied to coffee shops such as Starbuck and Quick Check located in Indonesia and abroad [29].

Based on the general quality requirements shown in table 1 above, in all samples of coffee from the origin of Ranah
Minang no found living insects and odorless bean and or mold smelly. Based on the coffee impurity fraction analysis results found in several samples, but still under the threshold of the coffee quality requirement of $0.5 \%$. Some samples are even completely undiscovered. There is the impurity, which indicates that the level of sorting has been done well. It is in line with the identification of post-harvest coffee handling by coffee farmers in West Sumatera. The smell is one of the determining parameters of coffee quality. The taste defects that should be avoided from coffee is the presence of stink, smell of soil (earthy), smell of fungus (moldy), smell of moss (musty), unpleasant acid taste (sour), smell of petroleum (oily), smell of chemicals (chemical) and smell of Smoke (smoky) [30].

4) Color and Small Value: The test is done by using the senses in the form of carefulness in the observing and smelling; good coffee beans have a fresh smell and bright colors and not contaminated with foreign materials, either causing discoloration or smell.

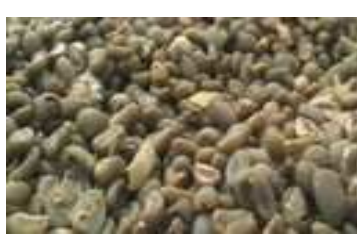

Solok

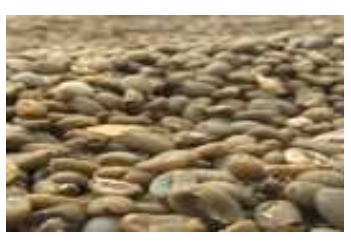

Solok Selatan

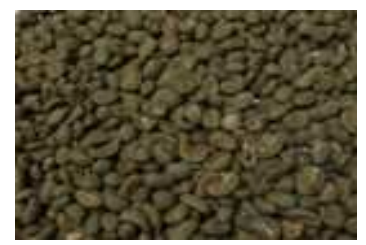

Pasaman Barat

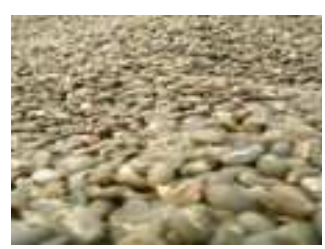

Agam

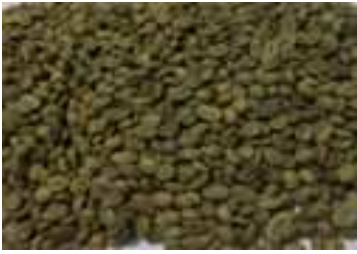

Limapuluh Kota

Fig. 4 Ranah Minang Coffee Beans Colors

5) Coffee Beans Size Value: Coffee beans used in the research of Ranah Minang Arabica coffee is from Solok Regency, South Solok, Pasaman, Agam, and Limapuluh Kota Regency. This test is done to determine the size of coffee beans, namely large bean size, medium bean size, small bean Size, and very small seeds/do not pass the screen (shells). The test is done using Screen consisting of several minimum levels of 4 levels. According to SNI 01-2907-2008, the quality requirement of coffee based on its size is divided into three size criteria, namely the large (not qualified to pass the diameter of $7.5 \mathrm{~mm}$ sieve/sieve No. 19, Medium (qualified to pass the diameter of $7.5 \mathrm{~mm}$ sieve, do not pass the sieve 6.5 $\mathrm{mm} /$ Sieve No.16), and small (qualified to pass sieve diameter 6.5 , not qualified to pass sieve diameter $5,5 \mathrm{~mm} /$ sieve No.14).

Some type of defects on a common coffee found and should be avoided by any coffee farmer is $\boldsymbol{a}$ ) Baked coffee; this defect occurs when the coffee is roasted too long with a low temperature without reaching the first crack. This defect cannot be seen with the naked eye. Generally, coffee with defects like this produces a flat coffee flavor, a little sweetness, or often described as a taste like fresh bread or paper. b) Underdeveloped Coffee, which is an imperfect coffee bean (underdeveloped), tends to have a grass-like flavor (grassy) or like eating a green plant stem. The most noticeable thing when doing this type of coffee cupping is the taste of muted acidity. c) Overdeveloped Coffee, this type of defect is the opposite of the underdeveloped. Between Overdeveloped and dark roast, the difference is very thin. However, when the roaster roasting the coffee is darker than the original goal, of course, this makes the coffee into a broken category (defect). The most obvious thing is the coffee result that has been roasted to be dark, close to black, and oily. The characteristic flavor that can be felt is bitter; it feels like eating charcoal/coal and leaving a less comfortable aftertaste. d) Quakers are a common type of defect found, especially when purchasing packaged coffee (whole beans). Quaker is an immature coffee bean and generally has a wrinkled surface. It is difficult to identify Quakers while still in the form of green beans. Quaker generally occurs because it is caused by bad soil conditions so that the essence of sugar and starch in coffee beans is not developed perfectly. Technically this is not a defect due to the roasting method, but generally, we can only find Quaker after the coffee is roasted. To get the maximum flavor of the coffee, the Quaker should be sorted and discarded. Otherwise, brewed coffee produces flavors such as paper, cereal, and dry. e) Overfermented, balanced coffee fermentation can produce an exotic and complex fruit flavor character and has an acidity like fresh grapes. However, if the fermentation is left for too long, it tastes like rotten fruit or vinegar. f) Baggy/Past Corp, this type of defect can be found when coffee beans are stored too long in bad condition. When sipping the coffee, it produces less savory flavor, such as cardboard or wood.

Overall, the coffee beans from Ranah Minang almost no one hundred percent can be declared zero defect, and always there are expressed defects or damaged beans in it. The sorting process can minimize it. To determine the quality of specialty coffee, coffee farmers in West Sumatera use the Defects Value system according to ICO's decision 
(International Coffee Organization). In this defect system, the more value of the defect, the quality of the coffee is lower, and the lower the defect's value, the quality of coffee is better. Specialty Coffee is the term for coffee with the highest grade because coffee is processed specifically with special provisions from the initial process of coffee is planted until it is served in a cup.

6) Fat Content: Ranah Minang Arabica coffee fat content can be seen in Table 2, indicating that the fat content is different for each variety. The amount of fat content contained in the coffee beans affects the flavor of the coffee.

TABLE II

West Sumatra Single ORIGIN ARABICA Coffee BeAns Fat CONTENT VARIOUS OF VARIETY

\begin{tabular}{cc}
\hline Sample Codes & Fat Content Average (\%) \\
\hline SC 1 & 2.75 \\
SC 2 & 2.93 \\
SC 3 & 3.11 \\
SC 4 & 3.14 \\
SC 5 & 2.26 \\
\hline
\end{tabular}

Arabica coffee's fat content is found in the cuticle, the beans protector, and coffee oil. In the cuticle contained five hydroxytryptophan fat acid from palmitic acid, Arachidate, Behenate, and Lignoserat. Fat on coffee is one of the chemical compositions of coffee that makes up the coffee flavor. The total fat content of the Arabica coffee is between 2-6\%, which is on the beans protector's cuticle. The increase of free fatty acids during storage causes rancidity on the coffee powder, affecting the flavor and lowering the coffee powder quality. Fat content produced is the same as rice coffee beans [31].

\section{B. Sensory Profile of Specialty Arabica Coffee in West Sumatera}

1) Quality diversity of coffee brewing: Planted Coffee grows in the area around the plateau in West Sumatra, precisely in Solok, South Solok, Pasaman, Agam, and Limapuluh Kota Regency. Coffee in Ranah Minang is also picked directly by hand by the farmers with the method of handpicking/selective pick. The natural condition of the Ranah Minang Highlands has a great influence on the quality of the aroma and flavor of the coffee produced. Ranah Minang coffee is a strong specific aroma between the combination of fresh fruits and spices. Another characteristic is its full body coffee character and has a sweet flavor like vanilla/caramel/hazelnut. The combination of pleasant taste is after taste.

The testing results of the quality of brewing characteristics show that the five local coffee origins (SC 1, SC 2, SC 3, SC 4 , and SC 5) can qualify for the specialty based on the flavor test protocol of the SCAA (minimum final score 80 ). The final score difference between counties is very thin. Similarly, the scores of each flavor attribute are almost identical to all cultivars. The condition does not reflect the diversity of seed size among the five samples. The seeds' size is not real correlates positively with the quality of flavor. The interesting thing is the Clean Cup, uniformity, and sweetness attributes for all the tested coffee origins obtain a maximum score (10) so that the category is extraordinary (exceptional). Many coffee aroma forming components, including the oil in coffee, have been roasted very sensitive to damage due to oxidation and hydrolysis.

Therefore, to suppress the damage, the oxygen and water access should be limited, for example, by vacuum packing of the powder or by modifying the air in the package with $\mathrm{C} 02$ or N2. Characteristics of the occurrence of aroma (and flavor) damage in the stored coffee are the smell of musty (staling) and rancid. In the process of brewing, most of the smell (fragrance) components of the coffee powder dissolve in water brewing. The volatilization of the smell component with moisture depends on the partition coefficient of each component. The volatile components carried by the water vapor is recognizable by the olfactory nerve in the nasal cavity when we were sipping (slurping) the coffee.

Based on the test result, the body attribute's highest score is given to the SC 3 sample code whose caffeine content is lower than SC 1, SC 2, SC 4, and SC 5. The results agree with James J. E (1991), who reports that coffee beans' caffeine content is negatively correlated with most of its flavor quality character. The caffeine content also proved to be not real positive correlates with flavor components [32,33,34], which directly affects the quality of coffee. The beans' physical characteristics are not really correlated with the caffeine content, so it cannot be used as an indirect identifier in the selection process. On the other, Salva (2011) argues that the body's attributes are closely correlated with protein and lipid content, while the caffeine content relates to the character of bitterness [35].

Although quantitatively, the fifth flavor of the Arabica coffee sample is almost identical, each has a unique aroma profile. The sample with the SC 1 coffee, SC 2 each has a distinctive aroma resembling lemon (lemony), while SC 3 and SC 4 each have a honey fragrance (honeyed). Spicy aroma is produced by SC 5 and SC1. Only SC 3, whose flavor makes a distinctive aroma resembling chocolate (chocolaty). It is suspected that the distinctive aroma ever attracted the roaster and gave a higher price at the farmer's level to the original coffee beans SC 1. The brew's distinctive fragrance is proven to provide added value to the produced coffee products. The difference in the content of volatile compounds can be caused by differences in roasting degrees and the difference in the proportion of the compounds found in coffee-related to the distinctive aroma of coffee. Many components are forming coffee aroma, including the oil in roasted coffee. Oil in coffee is very sensitive to damage, mainly due to oxidation and hydrolysis. Therefore, to suppress the damage, the oxygen and water access should be limited, for example, by vacuum packing of the powder or by modifying the air in the package with $\mathrm{C} 02$ or N2. Characteristics of the occurrence of aroma (and flavor) damage in the stored coffee are the smell of musty (staling) and rancid [36].

A variety of specialty coffee products then emerge as higher consumers demand to one of the coffee quality variables. The term of specialty coffee is intended for Arabica coffee products in certain regions with prominent distinctive properties in stable quality, especially processed by the roaster, and explicitly traded in the form of roasted coffee, ground coffee, or coffee as a brew in specific retail markets [37]. The determination of specialty coffee in Indonesia is still based on development (origin). The availability of broad genetic diversity provides the opportunity to conduct 
specialty coffee single cultivar-based selection, which grows in specific locations (single origin). Based on the previous study results, there has been a diversity of physical quality characteristics, Biochemic, and flavors among the Arabica coffee cultivar [38], [39]. Overseas, coffee beans derived from single cultivars have been marketed as specialty coffees. Current product identification and certification can even be done with the help of molecular markers. With the advent of a new single cultivar-based specialty coffee, farmers are expected to obtain incentives in the form of higher prices for the crops of the cultivars concerned.

2) Cupping Test Value: All coffee samples are highquality samples that have all been scored as "specialty" coffee, according to the Specialty Coffee Association of America (SCAA) cupping guidelines by four certified assessors. Fresh roasted samples were obtained and stored as whole seeds at room temperature in the Payakumbuh State Agricultural Polytechnic quality testing laboratory with a tightly impenetrable PVC bag. Samples were tested within 3 weeks. The short time for testing is to ensure that minimal conversion of compounds to thiols that can result in "staling" of coffee after roasting occurs [40]. The descriptive sensory panel consists of four highly trained panelists from the Indonesian Coffee and Cocoa Research Center. Each panelist has completed 120 hours of general descriptive analysis panel training with various coffee products. Training includes techniques and practice in attribute identification, terminology development, and intensity assessment. Besides, panelists have more than 2000 hours of testing experience with various food and beverage products.

An additional 6 hours of orientation time that included a focus on coffee attributes and included some samples from this study were held to provide further coffee-focused orientation. Similar panels have been used or in another research [41]. Sensory test to know the profile of Ranah Minang Specialty Arabica coffee is done by the Cupping method. Cupping coffee is a method used to assess the taste of the coffee. Because each type of coffee has several different characteristics, so cupping coffee is felt good enough to distinguish the coffee characteristics. The cupping method of coffee is done to know a person's sensitivity through the aroma and despair of the coffee that is tested by relying on the sense of smell and sense of taste (mouth). Coffee Tasting Test (Cupping) is well known in the mid-19th century in San Francisco. Besides, some are tested to know the characteristic of coffee is the fragrance (dried smell of coffee), aroma, flavor (typical smell of coffee), body (viscosity), acidity (sour taste), aftertaste (sense of taste), sweetness (sweetness), balance (balance of taste and aroma), clean cup (clean coffee), uniformity (consistency of flavor), overall and defects (delicious or not flavor produced). Some characteristics of the assessment of coffee cupping method are aroma (fragrance), the aroma of coffee that is sniffed, that is, the dried smell of coffee beans that have not been brewed but have been finely ground and smelled wet from coffee beans that have been brewed. The taste criterion is also an attribute of product quality that is considered the most important according to the research of Ranitaswari et al. [42]. The next consideration is the criteria for sweetness, which ranks second in the importance of sensory taste selection. This means that the level of sweetness or having a slightly sweet taste is considered preferred by the panelists based on the level of preference for the taste of the Minang coffee produced. According to Dairobbi [43], the criteria for sweet taste is one of the most important criteria in assessing the sense of taste in Minang Arabica coffee. Moreover, the sweet taste provides its own sensation from the natural taste produced.

The tongue detects flavor; this process the tongue is used to translate what has been the smell of the coffee or not. The flavor is a combination of perception that is recognized by the tongue and aroma, which is recognized by the overall smell organ. The flavor component of coffee is the main element of the coffee brewing value, as it covers two aspects at once. In organoleptic Assessment generally, the flavor is usually associated with other effects such as temperature, coarse/fine, etc. In the assessment of coffee flavors usually only include the flavor and aroma in unison and intact. It is true that other elements such as the heat level of the brewing also determine especially the aroma, which is associated with the level of volatility of the aroma-forming compounds. The cooler is usually the weaker the aroma value due to the lower the number of volatile compounds in brewing water vapor. Therefore, in the assessment of coffee brewing is usually in the condition that is quite hot or warm $\left( \pm 65^{\circ} \mathrm{C}\right)$. For flavor can be done together with aroma, acidity, and after taste. After taste is detected when the first time to drink coffee, it feels like there is a taste left in the base of the tongue or when swallowed, it just passing, and to judge it, the less taste is left, then the better its Value.

Acidity is the process of sensing the acidic presence of coffee while sipping. In addition to the flavor, the assessment of coffee is known as Body element, which is the level of the flavor concentrations of coffee brew. It can easily be imagined between a light coffee (flat) with a heavy coffee. The body value of a coffee is determined by the compounds that are water-soluble when brewed. Compounds such as carbohydrate groups, aromatic compounds, alkaloids, and oils greatly determine a coffee's body. The higher the compounds that dissolve or form a colloid in a brew fluid than the higher the coffee's body value. Thus, the body is usually associated with viscosities (viscosity) of liquids, strength (imaginary), and slippery or rough properties from the brewing fluid. The body referred to here is the thick or light of coffee when it was sipped. Assessment, if the body is thick, then the value to be given should be greater. The body can be given if it is not very fond of coffee; it cannot be too distinguishing whether the coffee body is thick or thin. Balance of some assessments such as flavor, after taste, and body. And if it is not a balance or less one of all the flavors that come mixed, then the given value is low. Sweetness, in the coffee, also has a sweet flavor, but the sweetness that is inflicted differs from sucrose's sweetness. The interaction between the taste and aroma components is usually prominent, but there is a balance. There is a particular coffee more acid (arabica in general) known as the acidity, but there is a more dominant coffee sweetness known as acidy.

Clean Cup, this is done at the start of the cupping method. And this assessment can be done coincide with the after taste: uniformity and uniformity between glass one. Overall, the overall assessment of all the characteristics that have been assessed, and the value becomes good when what is felt and 
sniffed as expected. Defects here is more to the flavor and aroma caused by the coffee. Cupping method has a distinctive way of implementation to get good results and satisfaction so that the flavor and aroma produced are not too tasteless or even too thick. The cupping method is carried out by weighing coffee as much as 8 grams, and the water measurement is given to $150 \mathrm{ml}$ of glass with a temperature of $90-95^{\circ} \mathrm{C}$. Then the coffee that is tasted of its flavor and aroma to be left for 4 minutes and not mixed with sugar at all during the cupping process. This is done so as not to damage the taste of the coffee itself.
Specialty Coffee is the term for coffee with the highest grade because the coffee is explicitly processed with special provisions start from the coffee is planted until it is served in a cup. Arabica coffee from the Ranah Minang can be said to be a specialty coffee because the condition of a coffee can be categorized as a special coffee grade is fulfilled. Coffee that is picked when harvested must be red-colored only, which is then processed into a green bean. It has a total defect of is lower than $4 \%$. If in $1 \mathrm{~kg}$ of green bean Specialty Coffee, then the total defect or the damaged beans should not be more than 40 grams. Green bean Specialty Coffee has a test cupping value of more than 80 .

TABLE III

The Profile of Ranah Minang Specialty Coffee Fully Washed Method

\begin{tabular}{|c|c|c|c|c|}
\hline Name of Coffee & altitude (mdpl) & Body & Acidity & Taste Profile \\
\hline Agam & $1250-1450$ & Medium & Low & Enough sweetness, spicy like cinnamon, herb, fruity \\
\hline Solok Selatan & $1100-1500$ & Medium & Medium & $\begin{array}{l}\text { Spicy, herb, vanilla, tea like, tamarin, Clean after taste, Sweet, fruity, } \\
\text { flowery, sugar browning, dried fruit, vinegar smell, sour, chocolate. }\end{array}$ \\
\hline Solok & $1250-1500$ & Medium & Medium & $\begin{array}{l}\text { sugar browning, dried fruit, vinegar smell, Sweet, fruity, flowery, lemon, } \\
\text { chocolate, herb, cinnamon after taste }\end{array}$ \\
\hline Pasaman & $1250-1450$ & Medium & Low & $\begin{array}{l}\text { Herb, dark chocolate, lemony, sugar browning, cinnamon after taste, } \\
\text { flowery, spicy, Green Apple, Citric acid, lime, sweet, ripe fruit, }\end{array}$ \\
\hline Lima Puluh Kota & $1000-1350$ & Medium & Low & Herb, enough sweetness spicy like cinnamon, herb. \\
\hline
\end{tabular}

South Solok is one of the areas in West Sumatera, which is famous for its coffee, which has a very wide area of coffee plantations. Coffee cultivation can now be said to be one of the principal professions for most residents there. No wonder if the interest in planting coffee in the South Solok population is increasing. That's why South Solok coffee is increasingly popular among Indonesian coffee lovers. Sumatera itself has many distinctive coffees. However, the South Solok is better known for its coffee than other regions in West Sumatra. In accordance with the region's name, this coffee is called South Solok Coffee. Although not as popular as Aceh coffee and other famous coffees, coffee is no fewer good results and can be enjoyed by coffee enthusiasts.

This coffee plantation is in the South Solok precisely between Twin Lakes and Mount of Talang. As it still includes Minang Land, this coffee is also known by the name of coffee Solok Minang. The South Solok coffee is planted close to the slopes of Talang Mountain. This area's altitude ranges from $1,200 \mathrm{M}$ to $1,600 \mathrm{M}$ Above the sea levels, which has a character of various flavors such as lemon, chocolate, spices, and spicy. Spices and spicy This is the most vicious taste of this coffee. Whatever its name, the coffee is well received by the wider community, not just in Sumatra but throughout Indonesia. Even when properly processed, the quality finds with coffee from other countries. In fact, this coffee is also sold to foreign countries. Solok Coffee is increasingly known for at least the last three years. The unique character makes this type of coffee fast-paced and, no wonder if this Solok specialty immediately turned into a new star in the class of Sumatran coffees (see Fig. 5).

The Body is among the low-medium, sweetness with a lot of notes such as tropical fruits and fruity aroma, flowery, lemon, chocolate, so in general, Solok Coffee tends to be like typical African coffee. Limapuluh Kota Regency coffee is almost like Minang Solok Coffee; the coffee production from Limapuluh Kota, especially from the district of Situjuah also increases significantly since the last three years. Arabica varieties have also gained more special attention from farmers since the year 2015. Situjuah Subdistrict of Limapuluh Kota regency is located around Mount of Sago; this area has an altitude of about $1200 \mathrm{M}-1450 \mathrm{M}$ above the sea level. Planting areas are scattered in several Nagari (district). Situjuah Coffee has a medium body, low acidity, and enough sweetness spices, exactly like cinnamon and herbs. One of the advantages of a wet processing method is fermentation and the cleansing of mucilage.

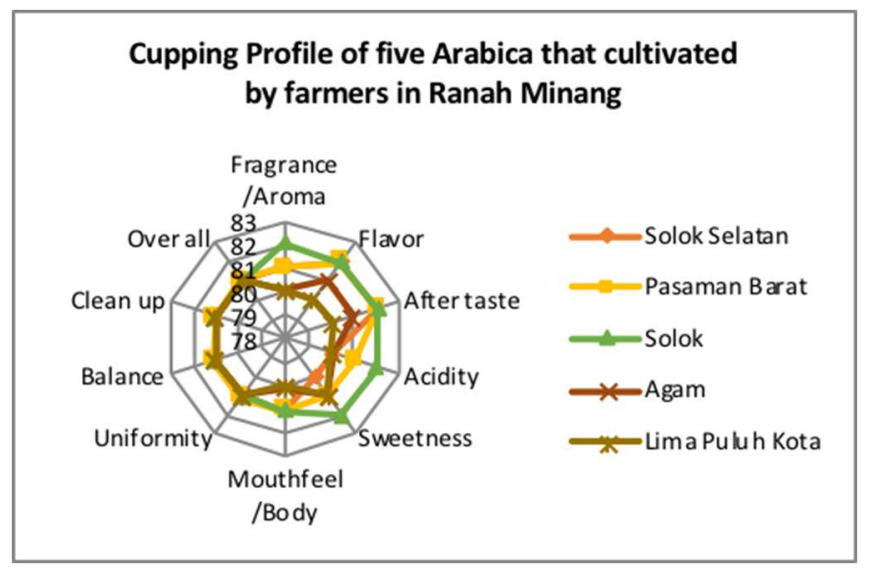

Fig. 5 Cupping profile of five Arabica coffees that cultivated by farmers in Ranah Minang, West Sumatra

The specialty coffee was introduced the first time in 1978 by Erna Knutsen at an international coffee conference in France. The concept is very simple: a special geographic micro-climate that produces coffee beans with a unique flavor profile. Specialty coffee is different from ordinary coffee because of its high quality or because the production process obtained certification such as Organic, Fairtrade, Utz Certified, Rainforest Alliance, cafe. Practices, Common Code for the Coffee Community (4C), Bird Friendly, and geographical indications. 
The main purpose of cupping is to ensure the best quality of the coffee that has been roasted. Cupping serves as an important method to identify defects caused by nature or that occur through coffee beans' processing. Not only roasting but can identify any coffee that goes into the category of defect. Other indicators in judging the flavor are the balance of taste, hygiene taste, and the uniformity of the main sense of coffee that can be displayed starting from the fragrance (dried ground coffee smell). The main taste defects should not be the smell of coffee beans such as soil odor, moldy (mildew odor), stuffy (moss odor), sour (sour taste), oily (oil odor), chemicals (chemical odor), smoky (smoke smell), etc.

The aroma aspect includes Fragrance (the smell of coffee when it is still dry) and aroma (smell of coffee when brewed with hot water). One can assess these criteria by three stages in the cupping, which is a) smell of different coffee powder in the bowl before pouring with water. b) Smell the scent while stirring the coffee surface of the brew. c) Smell the coffee aroma when coffee is dissolved. The quality of the special aroma is influenced by the aroma of the dried coffee beans, stirring, and the aroma of the coffee after the coffee is dissolved has a value of 5 vertical scales on the form. The final value must be based on all three aspects: aroma (delicious smell), flavor (typical coffee smell). The flavor shows the special properties between the scent was the first kiss with acidity and ended with an after taste. Flavor is a combination of the tongue and steam aroma of the nose that flows from the mouth to the nose. The value given to flavor should include the influence, quality, and complexity of the combined flavor and aroma when the coffee is sipped into the mouth firmly so that it involves the entire palate in judging.

The Body is based on the flavor when the fluid enters the mouth between the tongue and palate. Most examples with the viscous body have high scores. Some examples with a lightweight body can also have good taste in the mouth. Coffee with a vicious body such as Sumatran coffee or coffee with a light body like Mexico coffee becomes a reference though different. Acidity (flavored sour taste), often described as an acidic flavor that is obviously tasty, or sour if not tasty. Good Acidity describing the coffee is delicious, sweet, and like the flavor of fresh fruit that is immediately felt at the time of coffee was sipped. Acidity that is too predominantly categorized is not tasty and inappropriate as an example to assess flavor. Sweetness, it's pleasant because coffee contains carbohydrates. The opponent of the sweetness in this context is sour, astringent, or raw. This Sweetness is not like the flavor of sucrose found in soft drinks.

After taste is the endurance of positive flavor (flavor and aroma) that comes from the palate of the mouth and survives after the coffee is discarded or swallowed. If the after taste is directly lost and not tasty, then given a low value, the final value is marked by a checklist on the horizontal scale should match the assessment benchmark based on the origin and other factors (temperature roasting and destination roasting, etc.). As in Kenyan coffee and low Acidity such as Sumatran Coffee, high acidity becomes a reference though different. Balance is all aspects of flavor, after taste, acidity, body that is balanced in the example is called balance. If one aspect is missing or exceeds on the samples causing the balance value is reduced.
The Clean Cup indicates the absence of negative values from the beginning of taste until after taste as the end. In judging these criteria should be noted from the beginning of taste until the fluid coffee is swallowed or discarded. Coffee from a bowl that has no flavor and aroma is removed. The value of 2 digits is given to each cup showing the Clean Cup. Uniformity, there is aroma uniformity from each bowl. Overall is an assessment that reflects the whole aspect above from an example that each assessor has felt. An example with a pleasing aspect but not fulfill the standard criteria is given a low value. Coffee that has the expected criteria and has a distinctive aroma such as from the Origin state, is given a high value.

\section{CONCLUSION}

The method of processing, the influence of cultivars, and the elevation of the place of analysis results indicate that there is no real interaction on the entire quality attribute, except for the aftertaste and body attributes and the total score. The growing place and the height of coffee affect the acidity, balance, overalls, and total score attributes.

\section{REFERENCES}

[1] Carvalho, F. M., \& Spence, C. Cup color influences consumers expectations and experience of tasting specialty coffee. Food Quality and Preference, 75, 157-169, 2019.

[2] Chambers, E., \& Koppel, K. Associations of volatile compounds with sensory aroma and flavor: The complex nature of flavor. Molecules, 18 (5), 4887-4905, 2013.

[3] Welde Michael, G., Alamerew, S., Kufa, T. Genetic Diversity Analysis of Some Ethiopian Specialty Coffee (Coffea arabica L.) Accessions for Cup Quality Attributing Traits. J. of Biology, Agriculture and Healthcare, 2015, Vol.5, No.5, 88-96.

[4] Fuller, M. and Rao, N. Z. The effect of time, roasting temperature, and grind size on caffeine and chlorogenic acid concentrations in cold brew coffee. Scientific Report 7: 17979, 2017.

[5] Flament, I. Coffee Flavor Chemistry. 1st Edn., John Wiley and Sons, New York, USA., Pages: 410, 2001.

[6] Carvalho, F. M., \& Spence, C. The shape of the cup influences aroma, taste, and hedonic judgments of specialty coffee. Food Quality and Preference, 68, 315-321, 2018.

[7] Guinard, J. X., \& Mazzucchelli, R. The sensory perception of texture and mouthfeel. Trends in Food Science \& Technology, 7(7), 213-219, 1996.

[8] Carvalho, A. Principles, and practice of coffee plant breeding for productivity and quality factors: Coffea arabica. Coffee Volume 4 Agronomy, 129-165. (Eds Clarke, R. J., and Macrae, R.). London: Elsevier Applied Science, 1998.

[9] Clifford, M. N. Chemical, and physical aspects of green coffee and coffee products. In Coffee: Botany, Biochemistry, and Production of Beans and Beverage. (Eds Clifford, M. N., and Willson, K. C.). Croom Helm, London, New York, and Sydney. pp. 305-374, 1985.

[10] Leroy, T., Ribeyre, F., Bertrand, B., Charmetant, P., Dufour, M., Montagnon, C., Maraccini, P. and Pot, D. Genetics of coffee quality. Brazilian Journal of Plant Physiology, 2006.

[11] B. Bertrand, R. Boulanger, S. Dussert, F. Ribeyre, L. Berthiot, F.Descroix, T. Joët. Climatic factors directly impact the volatile organic compound fingerprint in green Arabica coffee bean as well as coffee beverage quality Food Chemistry, 135 (4) (2012), pp. 25752583,2012

[12] Joon-Kwan Moon and Takayuki Shibamoto. Role of Roasting Conditions in the Profile of Volatile Flavor Chemicals Formed from Coffee Beans. Journal of Agricultural and Food Chemistry, 57 (13), 5823-5831, 2009.

[13] Moreira Sobreira, Fabricio; Baiao de Oliveira, Antonio Carlos; Alves Pereira, Antonio; Coelho Sobreira, Milene Francisca, and Sakyiama, Ney Sussumu. Sensory quality of arabica coffee ('Coffea arabica') genealogic groups using the sensorgram and content analysis [online]. Australian Journal of Crop Science, Vol. 9, No. 6, Jun 2015: 486-493. 
[14] S. Jha, C.M. Bacon, S.M. Philpott, R.A. Rice, V.E.Méndez, P. Laderach, 1011 A review of ecosystem services, farmer livelihoods, and value chains in shade coffee agroecosystems B.W. Campbell, S Lopez-Ortiz (Eds.), Integrating agriculture, conservation, and ecotourism: examples from the field, Springer, New York (2011), pp. 141-208.

[15] C. Kremen, A. Iles, C. BaconDiversified farming systems: An agroecological, systems-based alternative to modern industrial agriculture Ecology and Society, 17 (4) (2012).

[16] Yusianto. Wet Process and dry process (West India Model/WIB), 2008.

[17] A., Wiryadiputra, S., Yusianto (eds.): Guide for cultivation and processing of Gayo Arabica coffee (In Indonesian: Panduan Budidaya dan Pengolahan Kopi Arabica Gayo). p142-147. ICCRI, Jember.

[18] BSN 2008 The Indonesian National Standard on coffee beans (SNI 012907-2008)

[19] Specialty Coffee Association of American (2015) Protocols. SCAA, Santa Ana, CA.

[20] Raghuramulu, Y., and R. Naidu, R. The Ochratoxin-A Contamination in Coffee and it's in Food Safety Issues, 2002.

[21] Ominski, K.H., R.R. Marquardt, R.N. Sinha, and D. Abramson. Ecological aspects of growth and mycotoxin production by storage fungi. In. J.D. Miller, and H.L. Trenholm. (eds). Mycotoxins In Grain: Compounds Other than Aflatoxin. Eagan, Minnesota, 1994.

[22] Pitt. J.I., A.D. Hocking, R.A. Samson, and A.D. King. Recommended Methods for Mycological Examination of Foods. In. R.A. Samson, A.D. Hocking, J.I. Pitt., and A.D. King. (eds). Modern Methods in Food Mycology. Elsevier, Amsterdam, 1992.

[23] Ramalakshmi, K., Kubra, I.R. and Rao, L.J.M. Physicochemical Characteristics of Green Coffee: Comparison of Graded and Defective Beans, Journal of Food Science, 72, S333-S337, 2007.

[24] Lin, C.C. Approach of Improving Coffee Industry in Taiwan-Promote Quality of Coffee Bean by Fermentation. The Journal of International Management Stu- dies 5, 154-159, 2010.

[25] Pereira, L.L., Guarçoni, R.C., Ferrão, M.A., Fonseca, A.F.A., and Caten, C.S.T. Los Caminos de la qualidade: Un estudio sobre la visión de Expertos e produtores rurales a respeto e processes y tecnologias. International Journal of Knowledge Engineering and Management (IJKEM), 6, 73-89, 2017.

[26] Feria-Morales, A.M. Examining the Case of Green Coffee to Illustrate the Limitations of Grading Systems/Expert Tasters in Sensory Evaluation for Quality Control. Food Quality and Preference, 13, 355367. https://doi.org/10.1016/S0950-3293(02)00028-9, 2002.

[27] Lee, L.W., Cheong, M.W., Curran, C., Yu, B. and Liu, Q.S Modulation of Coffee Aroma via the Fermentation of Green Coffee Beans with Rhizopus oligos- porus: I. Green coffee. Food Chemistry, 211, 916-924. https://doi.org/10.1016/j.foodchem.2016.05.076, 2016.

[28] Di Donfrancesco, B., Gutierrez G.N., and Chambers, E. 9 Comparison of Results from Cupping and Descriptive Sensory Analysis of
Colombian Brewed Coffee. Journal of Sensory Studies, 29, 301-311, 2014.

[29] Sihombing, L. The Agricultural Trading System, North Sumatera University Press, Medan [online] http://usupress.usu.ac.id, 2010.

[30] Sumarlin. Efforts to Improve the Quality of Coffee Beans. https: // disbunlambar. wordpress.com/2007/10/30/mutu- biji-kopi-lampung barat, 2007.

[31] Rita C. Alves, Cristina M.D. Soares, M. Beatriz P.P. Oliveira. Isoflavones in Coffee. 143-148, 2015.

[32] James, J. E. Caffeine, and Health. Academic, San Diego, 1991.

[33] Ashihara, H., Sano, H. and Crozier, A. Caffeine, and related purine alkaloids: biosynthesis, catabolism, function, and genetic engineering. Phytochemistry 69, 833-1076, 2008.

[34] Clifford, M.N. Chemical and physical aspects of green coffee and coffee products. Coffee: Botany, biochemistry, and production of beans and beverage. Westport, Connecticut, USA, AVI Publishing, 1985.

[35] Silvarolla, M.B., Mazzafera, P. and Fazuoli, L.C. A naturally decaffeinated arabica coffee. Nature 429, 826, 2004.

[36] F.M. Borém, G.W. Nobre, S.M. Fernandes, R.G.F.A. Pereira, P.D.OliveiraAvaliação sensorial do café cereja descascado, armazenado sob atmosphere artificial e convencional Ciência e Agrotecnologia, pp. 1724-1729, 2008.

[37] Coffee: RW Thurston, J. Morris, S. Steiman. Coffee. A comprehensive guide to the bean, the beverage, and the industry, 2013.

[38] Bult, J. H., de Wijk, R. A., \& Hummel, T. Investigations on multimodal sensory integration: Texture, taste, and ortho-and retronasal olfactory stimuli in concert. Neuroscience Letters, 411(1), 6-10, 2007

[39] Dijksterhuis, G. Multisensory flavor priming. Multisensory flavor perception (pp. 133-153). Cambridge, UK: Woodhead Publishing,2016.

[40] Dulsat-Serra, N., Quintanilla-Casas, B., \& Vichi, S. (2016). Volatile thiols in coffee: A review on their formation, degradation, assessment, and influence on coffee sensory quality. Food Research International, 89, 982-988.

[41] Jaffe, T. R., Wang, H., \& Chambers, E. IV (2017). Determination of a lexicon for the sensory flavor attributes of smoked food products. Journal of Sensory Studies, 32, e12262.

[42] Ranitaswari PA, Mulyani S, Sadyasmara CAB, 2018. Analisis Kepuasan Konsumen Terhadap Kualitas Produk Kopi dan Kualitas Pelayanan menggunakan Metode Importance Perfomance Analysis (Studi Kasus Di Geo Coffee) [Analysis of Consumer Satisfaction of Coffee Product Quality and Service Quality using the Importance Performance Analysis Method (Case Study in Geo Coffee)], Jurnal Rekayasa dan Manajemen Agroindustri, 6(2), 147-157. (in Indonesia)

[43] Dairobi A, Irfan I, Sulaiman I. 2017. Kajian Mutu Wine Coffee Arabika Gayo [Quality Study Wine Coffee Arabika Gayo], Jurnal Ilmiah Mahasiswa Pertanian Unsyiah, 2(4), 822-829. (in Indonesia) 